\title{
HUBUNGAN PARITAS DAN DUKUNGAN SUAMI DENGAN RENDAHNYA MINAT PENGGUNAAN ALAT KONTRASEPSI METODE TUBEKTOMI DI PUSKESMAS TIBAWA
}

\author{
Rindasri Bahu1 ${ }^{1}$ Erfina Hasania², Fendrawaty Hilamuhu ${ }^{3}$ \\ 1,2,3) Program Studi D-IV Bidan Pendidik Universitas Muhammadiyah Gorontalo \\ Gorontalo 96181, Indonesia \\ Email : Rindasari@yahoo.co.id
}

\begin{abstract}
The research aims to analyze the correlation of parity and husband support with low interest in use contraceptive tubektomi at Puskemas Tibawa. This research used observation analytics method with cross-sectional approach. Based on the result of statistical test $\rho$ Value $<0,05$ based on research result there is the correlation of parity and husband support with low interest in use contraceptive tubektomi at Puskemas Tibawa thus $\mathrm{H}_{0}$ is rejected.
\end{abstract}

Keywords: Parity, Husband Support, Tubektomi.

Abstrak

Tujuan penelitian menganalisa Hubungan paritas dan dukungan suami dengan rendahnya minat penggunaan alat kontrasepsi tubektomi di Puskesmas Tibawa. Hubungan paritas dan dukungan suami dengan rendahnya minat penggunaan alat kontrasepsi metode tubektomi di Puskesmas Tibawa. Penelitian ini menggunakan metode observasi analitik dengan pendekatan cross-sectional. Berdasarkan hasil penelitian, hasil uji statistik $\rho$ Value $<0,05$ Berdasarkan hasil penelitian ada hubungan paritas dan dukungan suami dengan rendahnya minat penggunaan alat kontrasepsi tubektomi di Puskesmas Tibawa. Sehingga $\mathrm{H}_{0}$ ditolak.

Kata Kunci : Paritas, Dukungan Suami, Tubektomi

\section{PENDAHULUAN}

Keluarga Berencana merupakan tindakan yang membantu individu atau pasangan suami istri untuk mendapatkan objektif tertentu, menghindari kelahiran yang tidak diinginkan, mengatur interval di antara kehamilan, mengontrol waktu saat kelahiran dalam hubungan suami istri dan menentukan jumlah anak dalam keluarga. Program Keluaraga Berencana berpotensi meningkatka status kesehatan wanita dan menyelamatkan kehidupannya. Hal tersebut dapat dilakukan dengan cara memungkinkan wanita untuk merencanakan kehamilan sedemikian rupa sebagai kontribusi dari hak reproduksi sehingga dapat menghindari kehamilan pada umur atau jumlah persalinan yang membawa bahaya tambahan dengan cara menurunkan kesuburan (Manurung, 2012). 
Kontrasepsi tubektomi memiliki angka kegagalan yang paling kecil (baik secara teoritis maupun praktek) dibandingkan dengan alat kontrasepsi lainnya. Secara teoritis angka kegagalan kontrasepsi tubektomi yaitu mencapai 0,04 kehamilan per 100 perempuan selama tahun pertama penggunaan dan dalam praktek angka kegagalan kontrasepsi tubektomi yaitu 0,1-0,5 kehamilan per 100 wanita dalam tahun pertama penggunaan. Berdasarkan laporan umpan balik pelayanan kontrasepsi januari 2013, jumlah kasus kegagalan untuk MKJP secara nasional tercatat sebanyak 288 kasus. Untuk metode kontrasepsi IUD jumlah kasus kegagalan 129 orang $(44,79 \%)$, tubektomi 26 orang $(9,03 \%)$, MOP 16 orang $(5,56 \%)$, dan implan 117 orang $(40,63 \%)$. Dengan demikian dapat diketahui bahwa jumlah kasus kegagalan terkecil MKJP untuk metode kontrasepsi wanita yaitu kontrasepsi tubektomi (Arum, 2011).

Kehamilan dan kelahiran terbaik artinya saat mempunyai resiko rendah untuk ibu yang jumlah kelahiran sedikit atau paritas rendah. Perempuan yang paritas banyak memerlukan kontrasepsi yang aman dan efektif untuk mengakhiri kelahiran karena kelompok ini akan mengalami peningkatan morbiditas dan mortalitas jika mereka hamil. Dalam pemilihan alat kontrasepsi, perempuan yang paritas banyak seperti grandemultipara, diarahkan pada Metode Kontrasepsi Jangka Panjang seperti tubektomi (Saifudin, 2010).

Langkah yang akan diambil untuk bisa mencapai target penurunan kelahiran dan lain-lain, antara lain Meningkatkan akses pelayanan KB MKJP (Metode KB Jangka Panjang/ tubektomi dan vasektomi) di Fasilitas layanan Kesehatan (fasyankes) di rumah sakit, Puskesmas dan jaringannya, dan DBS yang memenuhi persyaratan yaitu satu desa minimal satu fasilitas pelayanan kesehatan yang mampu melayani $\mathrm{KB}$ tubektomi, Meningkatkan akses dan promosi dan pelayanan KB tubektomi di setiap kecamatan, Intensifikasi dan eksentifikasi penggarapan dan pembinaan kelompok KB tubektomi satu kabupaten minimal satu kelompok, Fasilitasi pelatihan medis teknis bagi provider dan pelatihan kepada tenaga medis, Pelestarian kesertaan ber- KB melalui pencitraan layanan, penerapan SOP dengan pemberdayaan tim Jaga mutu(Witjaksono, 2013).

Meskipun program penggunaan alat kontrasepsi tubektomi sudah masuk dalam berbagai program pemerintah namun angka pencapaian akseptor KB tubektomi masih rendah. Penggunaan kontrasepsi masih didominasi oleh alat kontrasepsi suntik, pil dan kondom. Dari data di atas proporsi akseptor yang memakai metode kontrasepsi tubektomi tergolong masih rendah dibandingkan metode yang lain. Rendahnya penggunaan Metode kontrasesi tubektomi dapat disebabkan karena beberapa faktor seperti, ketidaktahuan peserta tentang kelebihan Metode kontrasepsi tubektomi, kualitas pelayanan KB dilihat dari segi ketersediaan alat kontrasepsi dan ketersediaan tenaga yang terlatih serta kemampuan medis teknis petugas pelayanan kesehatan, biaya pelayanan Metode kontrasepsi Jangka Panjang yang mahal, adanya hambatan dukungan dari suami dalam pemakaian Metode kontrasepsi 
tubektomi, dan adanya nilai yang timbul dari adanya sikap yang di dasarkan kepercayaan dan normanorma di masyarakat (Handayani, 2010).

Bentuk partisipasi suami dalam penggunaan alat kontrasepsi adalah mendukung istri dalam memilih alat kontrasepsi dan memberikan kebebasan kepada istri untuk menggunakan kontrasepsi tersebut.Setiap akseptor menggunakan kontrasepsi yang saat ini dipakai, dengan pertimbangan berbagai hal.Faktor yang memengaruhi pemilihan kontrasepsi yaitu berupa faktor internal berupa pengetahuan, pendidikan, umur, pekerjaan, paritas dan sikap.Faktor eksternal yaitu dukungan suami, dukungan keluarga, tenaga kesehatan, ekonomi dan sosial budaya(BKKBN, 2013).

Wawancara dengan Bidan desa Puskesmas Tibawa berkaitan dengan masalah dukungan suami, ibu akseptor KB yang menggunakan kontrasepsi atas pilihan sendiri, cenderung pernah berganti-ganti metode sampai 2-3 kali dengan alasan merasa kurang cocok dan ada keluhan dari suami. Sedangkan yang mendapatkan dukungan suami cenderung tetap menggunakan satu jenis kontrasepsi. Dalam pemilihan kontrasepsi memang tidak hanya dipengaruhi oleh dukungan suami saja, tetapi faktor akseptor itu sendiri dan faktor luar yang lain. Tetapi dukungan suami merupakan faktor utama karena suami sebagai partner dapat merasakan dampak langsung maupun tidak langsung dari penggunaan kontrasepsi oleh istri.

Hasil studi pendahuluan yang dilakukan, dari hasil pengguna KB tersebut tertinggi masih menggunakan suntik, sedangkan anjuran pemerintah saat ini adalah kontrasepsi jangka panjang. Kemudian hasil wawancara dengan 10 orang ibu yang paritas banyak yang menggunakan kontrasepsi suntik menimbulkan keluhan berat badan, tetapi walaupun menimbulkan keluhan mereka tetap memilih KB suntik karena ada dukungan dari suami. Dari 10 orang yang di wawancarai hampir seluruhnya mengatakan bahwa mereka sudah mendapatkan penjelasan tentang tubektomi sesuai anjuran pemerintah namun tidak ada dukungan dari suami, maka suami khawatir akan keadaan istrinya jika dilakukan operasi.Akseptor KB yang menggunakan Implant dan IUD, maka suami belum bisa menerima perubahan siklus menstruasi, sehingga terganggu pola hubungan sexualnya.

World Health Organization, 2014 pengguna kontrasepsi telah meningkat dibanyak bagian dunia, terutama di Asia dan Amerika Latin dan terendah di Sub-Sahara Afrika. Secara global, pengguna kontrasepsi modern telah meningkat tidak signifikan pada tahun 2014. Secara regional proporsi pasangan usia subur 15-49 tahun melaporkan pengguna metode kontrasepsi modern telah meningkat minimal 6 tahun terakhir. Di Afrika dari $23,6 \%$ menjadi $27,6 \%$, di asia telah meningkat dari $60,9 \%$ menjadi 61,6\% (Apriana, 2012).

$$
\text { Peserta KB baru secara }
$$
nasional tahun 2015 yaitu persentasenya adalah peserta suntik $(49,93 \%)$, peserta pil $(26,36 \%)$, peserta implant $(9,63 \%)$, peserta IUD $(6,81 \%)$, peserta kondom $(5,47 \%)$, peserta metode operasional wanita 
(MOW) $(1,64 \%)$, dan peserta metode operasional pria (MOP) $(0,16 \%)$ (Profil Kesehatan Indonesia, 2015). Hasil Survei Demografi dan Kesehatan Indonesia (SDKI) tahun 2012, pemakaian alat kontrasepsi yang baru mencapai $62 \%$ (58\% menggunakan kontrasepsi modern) dan 4 persen menggunakan kontrasepsi tradisional. Masyarakat masih banyak menggunakan alat kontrasepsi jangka pendek, padahal alat KB jangka pendek resiko kegagalannya cukup tinggi.

Data dari dinas kesehatan provinsi gorontalo peserta KB suntik sebanyak 45381 peserta, pil 42008 peserta, implant 14200 peserta, kondom 1373 peserta,IUD sebanyak 4251, tubektomi 3,53\%, vasektomi $0,69 \%$ dan KB aktif berjumlah 149593, dari jumlah PUS 210491. ini berarti pengguna tubektomi dan vasektomi masih tergolong kurang jika dibandingkan dengan peserta alat kontrasepsi pil dan suntik(Dinas Kesehatan Provinsi Gorontalo, 2016). Jika dilihat dari data Dinas Kesehatan Kabupaten Gorontalo, dari 21 puskesmas peserta tubektomi yang masih sedikit terdapat pada 8 puskesmas yaitu, Puskesmas Buhu sebanyak 0 peserta, Puskesmas Tibawa sebanyak 1 peserta, Puskesmas Asparaga sebanyak 0 peserta, Puskesmas Mootilango 0 peserta, Puskesmas Tolangohula 0 peserta, Puskesmas Bilato 0 peserta. Berdasarkan survei awal yang dilakukan di Puskesmas Tibawa dari 3800 jumlah pus, yang menggunakan tubektomi hanya 1 peserta, (Dinas Kesehatan Kabupaten Gorontalo, 2016).

Berdasarkan data di atas, peneliti tertarik untuk mengambil judul penelitian "Hubungan paritas dan dukungan suami dengan rendahnya minat penggunaan alat kontrasepsi tubektomi di Puskesmas Tibawa"

\section{METODE PENELITIAN}

Penelitian ini dilaksanakan pada bulan September 2017 di Puskesmas Tibawa

Penelitian yang digunakan adalah penelitian observasional analitik dengan menggunakan pendekatan cross sectional, yaitu peneliti melakukan pengumpulan data dalam waktu yang bersama atau dalam waktu tertentu (Notoatmodjo, 2012).

Variabel bebas dalam penelitian ini adalah paritas dan dukungan suami (Sugiono, 2011).

Variabel terikat dalam penelitian ini adalah penggunaan alat kontrasepsi tubektomi (Notoadmodjo, 2012).

Populasi dalam penelitian ini adalah seluruh akseptor KB di Puskesms Tiabawatahun 2017 dari bualn Januari- Juli yaitu sebanyak 62 peserta

Sampel yang digunakan dalam penelitian ini adalah teknik total sampling jumlah keseluruhan populasi adalah sampel (Notoadmodjo, 2012). DiPuskesmas

TibawaKabupatenGorontalo yang berjumlah 62 orang.

\section{HASIL PENELITIAN}

Karakteristik Responden

Berdasarkan hasil penelitian yang disajikan pada Tabel 1, diperoleh diketahui responden umur terbanyak yaitu kelompok umur 20-35 tahun yakni sebanyak 49 responden (79\%).

Berdasarkan tabel 2 di atas, 
diperoleh pendidikan terbanyak yaitu pendidikan rendah 51 responden (82,3\%).

Berdasarkan tabel 3 di atas, diperoleh pekerjaan terbanyak yaitu tidak bekerja tahun 58 responden (93,5\%).

Berdasarkan tabel 4 di atas, diperoleh jumlah Paritas terbanyak adalah multipara 28 responden $(45,2 \%)$, primipara 33 responden(53,2\%) dan grandemultipara 1 responden $(1,6 \%)$ dari 62 yang menjadi responden.

Berdasarkan tabel 5 di atas, diperoleh dukungan suami terbanyak adalah suami yang tidak mendukung 59 responden $(95,12 \%)$ dan mendukung 3 responden $(4,8 \%)$ dari 62 yang menjadi responden.

Tabel 1. Umur Responden

\begin{tabular}{lcc}
\hline $\begin{array}{l}\text { Umur lbu } \\
\text { (Tahun) }\end{array}$ & Jumlah & Presentase \\
\hline$<20$ & 5 & 8.1 \\
$20-35$ & 49 & 79 \\
$>35$ & 8 & 12.9 \\
\hline Total & 62 & 100 \\
\hline
\end{tabular}

Sumber: Olahan data primer (2017).

Tabel 2. Pendidikan Responden

\begin{tabular}{ccc}
\hline Pendidikan & Jumlah & Presentase \\
\hline Rendah & 51 & 82.3 \\
Tinggi & 11 & 17.7 \\
\hline Total & 62 & 100 \\
\hline Sumber: Olahan data primer (2017).
\end{tabular}

Tabel 3. Pekerjaan Responden

\begin{tabular}{ccc}
\hline Pekerjaan & Jumlah & Presentase \\
\hline $\begin{array}{c}\text { tidak } \\
\text { bekerja }\end{array}$ & 58 & 93.5 \\
Bekerja & 4 & 6.5 \\
\hline Total & 62 & 100 \\
\hline
\end{tabular}

Sumber: Olahan data (2017).

Tabel 4. Distribusi responden menurut paritas

\begin{tabular}{|c|c|c|c|}
\hline \multicolumn{2}{|l|}{ Paritas } & Jumlah & Presentase \\
\hline \multicolumn{2}{|c|}{ Primipara } & 33 & 53.2 \\
\hline \multicolumn{2}{|c|}{ Multipara } & 28 & 45.2 \\
\hline \multicolumn{2}{|c|}{ Grandemultipara } & 1 & 1.6 \\
\hline \multicolumn{2}{|c|}{ Total } & 62 & 100 \\
\hline \multicolumn{4}{|c|}{ Sumber: Olahan data primer (2017). } \\
\hline Tabel 5. & & \multicolumn{2}{|c|}{ menurut dukungan suami } \\
\hline \multicolumn{2}{|c|}{$\begin{array}{l}\text { Dukungan } \\
\text { Suami }\end{array}$} & Jumlah & Presentase \\
\hline \multicolumn{2}{|c|}{$\begin{array}{c}\text { Tidak } \\
\text { mendukung }\end{array}$} & 59 & 95.12 \\
\hline \multicolumn{2}{|c|}{ Mendukung } & 3 & 4.8 \\
\hline \multicolumn{2}{|c|}{ Total } & 62 & 100 \\
\hline
\end{tabular}

Sumber: Olahan data primer (2017).

Penggunaan Tubektomi

Berdasarkan Tabel 6, diperoleh informasi penggunaan tubektomi terbanryak adalah tidak menggunakan tubektomi 61 responden $(98,4 \%)$ dan yang menggunakan tubektomi 1 responden (1,6\%) dari 62 yang menjadi responden.

Tabel 6. Distribusi responden menurut penggunaan tubektomi

\begin{tabular}{ccc}
\hline $\begin{array}{c}\text { Penggunaan } \\
\text { Tubektomi }\end{array}$ & Jumlah & Presentase \\
\hline $\begin{array}{c}\text { Tidak } \\
\text { menggunakan } \\
\text { tubektomi }\end{array}$ & 61 & 98.4 \\
$\begin{array}{c}\text { Menggunakan } \\
\text { tubektomi }\end{array}$ & 1 & 1.6 \\
\hline Total & 62 & 100 \\
\hline
\end{tabular}

Sumber: Olahan data primer (2017). 
Tabel 7 Hubungan paritasdenganrendahnya minat penggunaan alat kontrasepsi tubektomi

\begin{tabular}{|c|c|c|c|c|c|c|c|}
\hline \multirow{3}{*}{ Paritas } & \multicolumn{4}{|c|}{ Penggunaan tubektomi } & \multicolumn{2}{|c|}{ Jumlah } & \multirow{3}{*}{$\begin{array}{c}P . \\
\text { value }\end{array}$} \\
\hline & \multicolumn{2}{|c|}{$\begin{array}{c}\text { Tidak } \\
\text { menggunakan } \\
\text { tubektomi }\end{array}$} & \multicolumn{2}{|c|}{$\begin{array}{c}\text { Menggunakan } \\
\text { tubektomi }\end{array}$} & & & \\
\hline & $\Sigma$ & $\%$ & $\Sigma$ & $\%$ & $\Sigma$ & $\%$ & \\
\hline Primipara & 33 & 53,2 & 0 & 0 & 33 & 53,2 & \\
\hline Multipara & 28 & 45,2 & 0 & 0 & 28 & 45,2 & \\
\hline Grandemultipara & 0 & 0 & 1 & 1,6 & 1 & 1,6 & 0,004 \\
\hline Total & 61 & 98,4 & 1 & 1,6 & 62 & 100 & \\
\hline
\end{tabular}

Sumber : Olahan data primer (2017).

Tabel 8 Hubungan dukungan suami dengan rendahnya minat penggunaan alat kontrasepsi tubektomi

\begin{tabular}{|c|c|c|c|c|c|c|c|}
\hline \multirow{3}{*}{$\begin{array}{l}\text { Dukungan } \\
\text { suami }\end{array}$} & \multicolumn{4}{|c|}{ Penggunaan tubektomi } & \multirow{2}{*}{\multicolumn{2}{|c|}{ Jumlah }} & \multirow[b]{2}{*}{$P$ value } \\
\hline & \multicolumn{2}{|c|}{$\begin{array}{c}\text { Tidak } \\
\text { menggunakan } \\
\text { tubektomi }\end{array}$} & \multicolumn{2}{|c|}{$\begin{array}{l}\text { Menggunakan } \\
\text { tubektomi }\end{array}$} & & & \\
\hline & $\Sigma$ & $\%$ & $\Sigma$ & $\%$ & $\Sigma$ & $\%$ & \\
\hline $\begin{array}{c}\text { Tidak } \\
\text { mendukung }\end{array}$ & 58 & 93,5 & 0 & 0 & 58 & 93,5 & 0,000 \\
\hline mendukung & 3 & 4,8 & 1 & 1,6 & 4 & 6,5 & \\
\hline Total & 61 & 98,4 & 1 & 1,6 & 62 & 100 & \\
\hline
\end{tabular}

Sumber : Olahan data primer Puskesmas Tibawa (2017).

Berdasarkan tabel 8paritas primipara yang tidak menggunakan tubektomi 33 responden (53,2\%).Multipara tidak menggunakan tubektomi 28 responden (45,2\%). Sedangkan grandemultipara yang menggunakan tubektomi 1 responden (1,6\%). Hasil uji statistik chi square dengan diperoleh nilai $\rho$ Value $0,004(\rho<0,05)$, dari nilai tersebut dapat dijelaskan bahwa $\mathrm{H}_{0}$ ditolak dan $\mathrm{H}_{\mathrm{a}}$ diterima artinya ada hubungan paritasdenganrendahnya minat penggunaan alat kontrasepsi tubektomi di Puskesmas Tibawa. mendukung tidak menggunakan tubektomi 58 responden (93,5\%), sedangkan suami mendukung tetapi tidak menggunakan tubektomi 3 responden $(4,8 \%)$ dan yang menggunakan tubektomi 1 responden $(1,6 \%)$.Hasil uji statistik chi square dengan diperoleh nilai $\rho$ Value 0,000 $(\rho<0,05)$, dari nilai tersebut dapat dijelaskan bahwa $\mathrm{H}_{0}$ ditolak dan $\mathrm{H}_{\mathrm{a}}$ diterima artinya ada hubungan dukungan suami dengan rendahnya minat penggunaan alat kontrasepsi tubektomi di Puskesmas Tibawa.

Berdasarkan Tabel 9 suami tidak 
Hubungan paritas dengan rendahnya minat penggunaan alat kontrasepsi tubektomi di Puskesmas Tibawa

Berdasarkan tabel paritas primipara yang tidak menggunakan tubektomi 33 responden (53,2\%).Multipara tidak menggunakan tubektomi 28 responden (45,2\%).

Sedangkan grandemultipara yang menggunakan tubektomi 1 responden $(1,6 \%)$. Hasil uji statistik chi square dengan diperoleh nilai $\rho$ Value $0,004 \quad(\rho<0,05)$, dari nilai tersebut dapat dijelaskan bahwa $\mathrm{H}_{0}$ ditolak dan $\mathrm{H}_{\mathrm{a}}$ diterima artinya ada hubungan paritasdengan rendahnya minat penggunaan Tubektomi adalah setiap tindakan pada kedua saluran telur wanita yang mengakibatkan wanita tersebut tidak akan mendapat keturunan lagi. Jenis kontrasepsi ini bersifat permanen, karena dilakukan penyumbatan pada saluran telur wanita yang dilakukan dengan cara diikat, dipotong ataupun dibakar (Yuliastri, 2010). Jenis-jenis Tubektomi terdiri dari Mini Laparotomi dan Laparoskopi. Mini-Laparotomi adalah tubektomi dengan sayatan yang dibuat digaris tengah atas simpisis sepanjang $3 \mathrm{~cm}$ sampai menembus peritoneum. Untuk mencapai tuba digunakan alat khusus (elavator uterus) ke dalam kavum uteri. Dengan bantuan alat tersebut uterus dalam keadaan retrofleksi dijadikan letak antefleksi dahulu kemudian didorong ke arah lubang sayatan, lalu dilakukan penutupan tuba dengan salah satu cara

Laparoskopimerupakan

tubektomi yang mula-mula dipasang cunam serviks pada bibir depan porsio uteri, dengan maksud supaya dapat menggerakan uterus jika hal tersebut diperlukan saat laparoskopi. Sayatan dibuat dibawah pusat sepanjang lebih dari $1 \mathrm{~cm}$. Kemudian ditempat luka tersebut dilakukan pungsi sepanjang rongga peritoneum dengan jarum khusus (jarum veres) dan melalui jarum itu dibuat pneumoperitoneum dengan memasukkan $\mathrm{CO} 2$ sebanyak 1 sampai 3 liter dengan kecepatan kirakira 1 liter permenit. Setelah jarum veres dikeluarka, troika dimasukkan laparoskopi melalui tabung. Dengan cunam yang dimasukkan dalam rongga peritoneum bersama laparoskop, tuba dijepit dan dilakukan penutupan dengan kauterisasi. Cara kerja dengan menutup atau oklusi tuba faloppi (mengikat dan memotong atau memasang cincin) ehingga spermatozoa tidak dapat bertemu dengan ovum.

Paritas 2 sampai 3 merupakan paritas paling aman ditinjau dari sudut kematian maternal. Paritas lebih dari 3 mempunyai angka kematian maternal lebih tinggi. Lebih tinggi paritas, lebih tinggi kematian maternal. Resiko pada paritas 1 dapat ditangani dengan asuhan obstetri yang baik, sedangkan resiko pada paritas tinggi dapat dikurangi atau dicegah dengan berKB. Seseorang yang berparitas lebih dari satu sudah seharusnya menjadi akseptor KB untuk mengatur atau menjarangkan kehamilannya,tetapi dewasa ini banyak akseptor KB yang masih mengalami kesulitan dalam menentukan pilihannya. Paritas diperkirakan ada kaitannya dengan arah pencarian informasi tentang pengetahuan ibu hamil, nifas/menyusui. Hal ini dihubungkan dengan pengaruh pengalaman sendiri maupun orang lain terhadap 
pengetahuan yang dapat mempengaruhi perilaku saat ini atau kemudian, pengalaman yang diperoleh dapat memperluas pengetahuan seseorang (Siregar, 2014).

Hasil penelitian yang didapatkan

di Puskesmas Tibawa memiliki kesesuaian dengan teori paritas karena semakin banyak jumlah anak maka semakin mengarah ke kematian maternal sehingga dapat dicegah atau dikurangi dengan memakai alat kontrasepsi yang memiliki keefektifan tinggi atau alat kontrasepsi jangka panjang. Hal ini dapat dilihat dari angka kematian maternal yang tinggi, karena pandangan setiap PUS banyak anak banyak rejeki. Selain itu sangat diperlukannya penyuluhan tentang alat kontrasepsi agar PUS lebih memiliki pengetahuan tentang perlunya alat kontrasepsi dan resiko nya jika terlalu memiliki banyak anak.

Asumsi peneliti paritas juga berhubungan dengan umur semakin tinggi paritas kemungkinan besar umur ibu tersebut juga semakin tinggi.Artinya umur berpengaruh dalam paritas seseorang.Dalam penelitian ini Berdasarkan tabel 2 di atas, diperoleh jumlah responden umur ibu terbanyak yaitu umur 20-35 tahun49 responden (79\%).

Penelitian ini sejalan dengan penelitian yang dilakukan (Herlinawati, 2012) menunjukkan hasil analisis hubungan paritas dengan pemakaian kontrasepsi tubektomi pada wanita PUS ditemukan sebanyak 6 akseptor $(26,1 \%)$ yang berparitas rendah (anak <3) yaitu memilih tubektomi sebagai alat kontrasepsi, sedangkan ibu yang berparitas tinggi sebanyak 44 akseptor $(69,8 \%)$ memilih tubektomi sebagai alat kontrasepsi. Secara statistik terbukti ada hubungan yang bermakna dari paritas ibu dengan pemakaian tubektomi $(p=0,001)$

\section{Hubungan dukungan suami dengan rendahnya minat penggunaan alat kontrasepsi tubektomi di Puskesmas Tibawa}

Berdasarkan tabel suami tidak mendukung tidak menggunakan tubektomi 58 responden (93,5\%), sedangkan suami mendukung tetapi tidak menggunakan tubektomi 3 responden $(4,8 \%)$ dan yang menggunakan tubektomi 1 responden $(1,6 \%)$.Hasil uji statistik chi square dengan diperoleh nilai $\rho$ Value 0,000 $(\rho<0,05)$, dari nilai tersebut dapat dijelaskan bahwa $\mathrm{H}_{0}$ ditolak dan $\mathrm{H}_{a}$ diterima artinya ada hubungan dukungan suami dengan rendahnya minat penggunaan alat kontrasepsi tubektomi di Puskesmas Tibawa.

Penggunaan kontrasepsi merupakan tanggung jawab pria dan wanita sebagai pasangan, sehingga metode kontrasepsi yang dipilih mencerminkan kebutuhan serta keinginan suami dan istri. Suami dan istri harus saling mendukung dalam penggunaan metode kontrasepsi karena keluarga berencana bukan hanya urusan pria atau wanita saja.

Dukungan suami diartikan sebagai sikap/ tindakan suami terhadap alat/ metode kontrasepsi yang digunakan istrinya. Termasuk saran suami mengenai alat/ metode kontrasepsi apa yang sebaiknya digunakan oleh istri.

Pada penelitian ini diketahui bahwa hampir seluruh suami tidak menyetujui alat kontrasepsi yang 
digunakan istrinya. Seluruh istri yang menggunakan kontrasepsi selain tubektomi, sedangkan itu tidak diberikan dukungan yang baik oleh suami. Responden yang menggunakan kontrasepsi tubektomi pun memiliki dukungan yang baik dari suami. Berdasarkan hasil tersebut diketahui bahwa suami memberi kebebasan dan dukungan kepada istri untuk menggunakan alat kontrasepsi sesuai dengan keinginan istri. Tetapi kategori dukungan baik adalah jika suami setuju, suami mendukung, serta kontrasepsi yang disarankan suami sama dengan yang digunakan oleh istri dan selalu mengikuti perkembangan tentang kontrasepsi yang digunakan.

Pada pengguna tubektomi, hanya 4 responden memiliki dukungan yang baik dari suami, sementara meskipun dukungan suami baik, sebagian responden lainnya lebih memilih untuk menggunakan kontrasepsi selain tubektomi. Dukungan yang baik namun belum membuat akseptor KB menggunakan tubektomi, diduga membuat tidak adanya hubungan antara dukungan suami dengan penggunaan kontrasepsi tubektomi.

Selain itu, dukungan yang baik namun belum membuat akseptor KB menggunakan tubektomi menunjukkan kesetaraan gender yang meningkatkan peran istri pada pengambilan keputusan dalam keluarga. Menurut instruksi Presiden No. 9 Tahun 2008, gender adalah konsep yang mengacu pada peranperan dan tanggung jawab laki-laki dan perempuan yang terjadi akibat dari dan dapat berubah oleh keadaan sosial dan masyarakat. Sementara yang dimaksud dengan kesetaraan gender adalah kesamaan kondisi bagi laki-laki dan perempuan untuk memperoleh kesempatan dan hakhaknya sebagai manusia, agar mampu berperan dan berpartisipasi dalam kegiatan politik,keamanan nasional, serta kesamaandalam menikmati hasil pembangunan ekonomi, sosial, budaya, pertahanan, dan tersebut.

Ketidaktahuan suami terhadap kontrasepsi tubektomi itu karena sebagian besar tidak mau tahu tentang $\mathrm{KB}$ yang digunakan istri.

Dalam Hartanto

diketahui ada dukungan positif antara persepsi kesetaraan gender pada lakilaki dengan keterlibatan istri pada pengambilan keputusan publik dalam rumah tangga. Semakin positif persepsi kesetaraan gender pada lakilaki akan diikuti pula dengan tingginya keterlibatan istri pada pengambilan keputusan publik dalam rumah tangga. Menurutnya, di dalam rumah tangga, pembagian peran antara suami dan istri mempengaruhi keterlibatan istri pada pengambilan keputusan publik. Persepsi kesetaraan gender pada laki-laki dapat diwujudkan dengan memberikan persamaan kesempatan sehingga istri mempunyai peran yang sama dalam pengambilan keputusan dalam rumah tangga.

Dapat disimpulkan bahwa dukungan suami yang baik belum tentu membuat seorang istri menggunakan kontrasepsi tubektomi. Dengan adanya kesetaraan gender pada pengambilan keputusan dalam keluarga, maka istri memiliki wewenang untuk memutuskan alat kontrasepsi apa yang akan 
digunakan.

\section{KESIMPULAN DAN SARAN KESIMPULAN}

1.Berdasarkan hasil penelitian ada hubungan

paritasdenganrendahnya minat penggunaan alat kontrasepsi tubektomi di Puskesmas Tibawa.

2. Berdasarkan hasil penelitian ada hubungan dukungan suamidenganrendahnya minat penggunaan alat kontrasepsi tubektomi di Puskesmas Tibawa.

\section{SARAN}

1. Bagi Peneliti Selanjutnya

Peneliti selanjutnya hendaknya lebih menambah atau mendalami tentang karakteristik PUS yang menggunakan kontrasepsi MOW dan menjadi dasar bagi penelitian lanjutan dan dapat menjadi salah satu bahan bagi penyempurna dalam pembelajaran khususnya dalam lingkup pelayanan KB.

2. Bagi Institusi Pendidikan

Diharapkan hasil penelitian ini dapat digunakan sebagai referensi dalam memberikan informasi dan pengetahuan tentang pengaruh pengetahuan dan dukungan suami terhadap peminatan penggunaan kontrasepsi tubektomi

3. Bagi Institusi Kesehatan (Bidan)

Diharapkan mampu menambah pengetahuan tentang pentingnya Alat Kontrasepsi. Menjadi referensi juga buat institusi lainnya.

\section{DAFTAR PUSTAKA}

Apriana.B, 2012. Faktor - Faktor Yang Berhubungan Dengan

Pemakaian Kontrasepsi Implant Pada Aseptor KB Dipuskesmas
Ciomas. Skripsi. Fakultas Kesehatan Masyarakat. Universitas Indonesia.

Arum, D.N.S dan Sujiyatini. 2011. Panduan Lengkap. Pelayanan $K B$ Terkini. Nuha medika. Yogyakarta.

BKKBN. 2013. Laporan umpan balik pelayanan kontrasepsi. Jakarta :Direktorat pelaporan dan statistik.

Dwi, R.2015, Hubungan Antara Dukungan Suami Dan Pengetahuan IbuDengan Pemilihan Alat Kontrasepsi Intra Uterine Device(IUD) Di Puskesmas Polokarto Kabupaten Sukoharjo. Artikel penelitian, Program Studi

Kesehatan Masyarakat. Fakultas IImu KesehatanUniveritas Muhammadiyah Surakarta.

Ermawan, E. 2012. Faktor-faktor yang berhubungan dengan pemilihan alat kontrasepsi suntik depomedroksiprogesteron asetat di Kelurahan Karang Tengah Sragen. Karya Tulis Ilmiah. Stikes Aisyiyah Yogyakarta.

Handayani, S., 2010. Buku Ajar Pelayanan Keluarga Berencana. Yogyakarta : Pustaka Rihama.

Hartanto.H.2013. Keluarga berencana dan kontrasepsi. Jakarta : pustaka sinar harapan.

Lestari, S, S. Sariyati, dan Wahyuningsih. 2015.

Pengetahuan Akseptor Tentang $K B$ Suntik 3 Bulan Dengan Ketepatan Waktu Kunjungan Ulang di BPRB Bina Sehat Kasihan, Bantul, Yogyakarta. Ners And Midwifery Indonesia. 3:104-110. 
Lestari, T. 2015. Kumpulan Teori Untuk Kajian Pustaka Penelitian Kesehatan. Nuha Medika. Yogyakarta.

Notoatmodjo S. 2012. Metodologi Penelitian Kesehatan. PT. Rineka Cipta. Jakarta

Saifudin, AB. 2010. Buku Panduan Praktis Pelayanan Kontraepsi. Jakarta : YBPSP

Sugiyono. 2011. Metode Penelitian Kuantitatif Kualitatif dan R\&D. Alfabeta CV, Bandung

Siregar, 2015. Hubungan Karakteristik, Pengetahuan Dan Dukungan Suami Terhadap Pemakaian Metode Kontrasepsi Jangka Panjang (MKJP) Pada Wanita Pasangan Usia Subur di Wilayah Kerja Puskesmas Medan Sunggal Kecamatan Medan Sunggal. Skripsi. Fakultas Kesehatan Masyarakat Universitas Sumatera Utara.

Witjaksono. 2013. IImu kebidanan. Jakarta : Yayasan Bina Pustaka Sarwono Prawirohardjo

Yuliasri, T. 2010. Hubungan Tingkat Pengetahuan Ibu Tentang Keluarga Berencana Dengan Pemilihan Alat Kontrasepsi Setelah Melahirkan Di Rskia Ummi Khasanah Bantul. Karya Tulis IImiah. Universitas Sebelas Maret Surakarta. Surakarta.

Manurung. 2012. Analisis Faktor Yang Memengaruhi Akseptor Kb Dalam Memilih Alat Kontrasepsi Iud Di Desa Wonosari Kecamatan Tanjung Morawa Kabupaten Deli Serdang. Jurnal. Fakultas IImu Kesehatan Masyarakat. Universitas Sumatra Utara 